Educational Psychology Library Lab Manual 



\title{
Educational Psychology Library Lab Manual
}

\author{
An Introduction to Searching the Uof A Library \\ Sources of Information
}

\author{
DENIS LACROIX
}




\section{다 (1) (\$) (2)}

Educational Psychology Library Lab Manual by Denis Lacroix is licensed under a Creative Commons Attribution-NonCommercial-ShareAlike 4.0 International License, except where otherwise noted. 


\section{Contents}

Introduction \& Learning Objectives 1

Part I. Chapter r: From Topic to Question

1.1 Finding Research Topic Ideas 5

1.2 Turning Your Topic into a Question 6

1.3 Finding Answers Using Background 7

Information Tools

Part II. Chapter 2: Searching for Known Titles

1. 2.1 Where to Start Searching for Known Titles 13

2.2 Searching the Library Catalog for a Known 14 Title

2.3 Reading a Catalogue Record 16

2.4 Book Title Searching Exercise 18

2.5 Finding Journal Articles and Book Chapter 19 Titles

2.6 Finding Journal Articles \& Book Chapters 22

Exercise

2.7 Using the GetIt Citation Linker to Find Source 24 Titles

Part III. Chapter 3: Topic Searching

3.1 Choosing the Right Tool for the Search Job 
3.1.1 Choosing the Right Tool Exercise

3.2 Combining Concepts for Topic Searching 30

3.3 Using Variant Terms to Describe your Topical 32

Concepts

3.4 Advanced Searching of the Library Catalog 34

3.5 Learning to Search the ERIC (Ebsco) Database 36

3.6 Searching PsycInfo (OVID) 41

3.7 Database Searching Exercises 44

Part IV. Chapter 4: Evaluating, Citing, and

Managing Your Sources

4.1 Evaluating Sources $\quad 49$

4.2 Citing Sources 51

4.3 Managing Sources $\quad 52$

4.4 Chapter Exercise $\quad 53$

AskUs $\quad 55$

$\begin{array}{ll}\text { Glossary } & 56\end{array}$ 


\section{Introduction \& Learning Objectives}

Welcome to the Library lab manual for Educational Psychology. The manual's purpose is to give you the foundational knowledge necessary to start searching for information in Educational Psychology using the University of Alberta Library's catalog and databases. The manual contains step by step instructions, videos, and examples. The successful completion of the objectives below will depend on answering the exercise questions and reviewing the examples whenever necessary.

Learning Objectives

After completing this tutorial, you will be able to:

- Formulate a research question from a topic

- Locate the full text of journal or book titles at the UofA Library

- Identify references to inform your research question(s) 

PART I

\section{CHAPTER I: FROM TOPIC TO QUESTION}

Learning Outcomes

After completing this chapter, you will be able to:

- Develop a research question from a topic 



\section{I.I Finding Research Topic Ideas}

The following video on Finding a research topic idea will demonstrate basic strategies for developing a research topic.

A video element has been excluded from this version 01 of the text. You can watch it online here:

https://openeducationalberta.ca/librarylabmanual/?p=5

- If you need more guidance on defining a research topic, please consult the SAGE Research Methods Project Planner. 


\section{I.2 Turning Your Topic into a Question}

- Turn your topic into a question that starts with either what, why, or how.

\section{Example question for EDPY:}

What is the foreign language proficiency of elementary-aged children with autism in Alberta schools?

- What other questions do you need to answer in order to answer your main question?

\section{Jot your other questions down, e.g.}

What inclusion indicators and standards exist for foreign language learning in Alberta schools?

For a more in depth look at research questions, please consult the SAGE Research Methods Project Planner. 


\section{I.3 Finding Answers Using Background Information Tools}

- Use background information tools, like dictionaries and encyclopedias, to find answers to some of the questions you noted in chapter 1.2 and note the alternative terminology used in discussing a topic.

\section{For example,}

What is foreign language proficiency?

- Consult the EDPY subject guide's Special Education background information section for suggestions of dictionaries, encyclopedias, and other reference titles to explore.
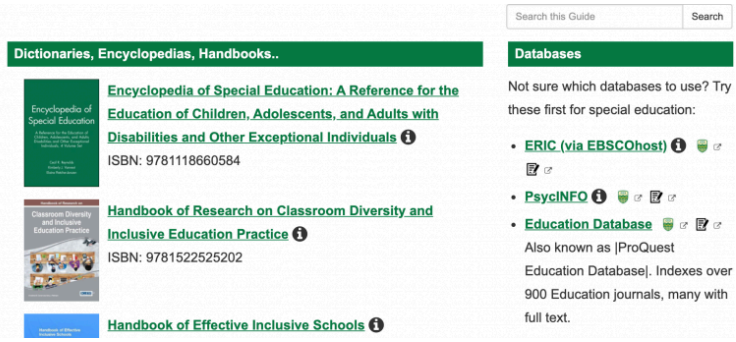

- For example, the EDPY Library guide includes The Encyclopedia of Special Education ${ }^{1}$ which, in the context of the 
research question, can provide a better understanding of the concept of foreign language proficiency.

- N.B. search the full text of the encyclopedia using the ebook's search box at the top right-hand corner to identify relevant chapters or browse its table of contents.
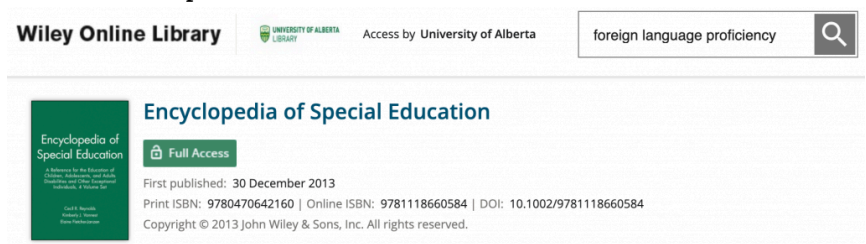

- The chapter on the The Cattell-Horn-Carroll Theory of Cognitive Abilities found in the search above uses words like grammatical sensitivity and crystallized intelligence which will help you later in building your searches and using alternate keywords.

Academic or scholarly works often have a bibliography or a list of references and works cited that you may consult for more information at the end of an article or chapter.

The Encyclopedia of Special Education's entry on "Bilingual Special Education" ${ }^{2}$ is an example of such writing where a list of references can be useful for more

1. https://search.library.ualberta.ca/catalog/6514012

2. https://doi-org.login.ezproxy.library.ualberta.ca/ $\underline{10.1002 / 9781118660584 . e s e 0327}$

8 | 1.3 Finding Answers Using Background Information Tools 
information. The $\mathbf{1}$ symbol in the image below will highlight such a cited reference.

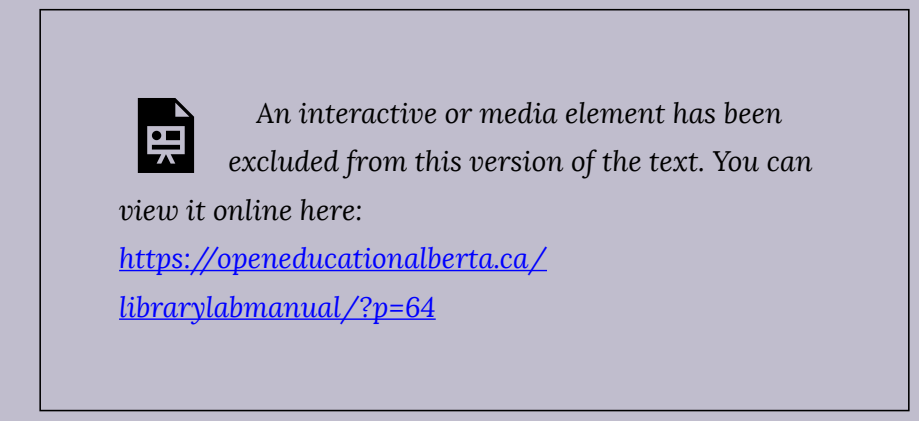

Finding the titles cited in a list of references is a result of what is called a known search. See the next chapter for searching for titles that you know exist.

- Another resource to explore is the Encyclopedia of Educational Psychology ${ }^{3}$ listed on the main EDPY library guide page. There are a number of other dictionaries, encyclopedias, handbooks, and manuals on a variety of topics that will broaden your perspective of your topic.

3. https://search.library.ualberta.ca/catalog/6148927 
\pm Full Download $\quad$ Encyclopedia of Educational Psychology

E. PDF Full Text

- To open and search the Encyclopedia of Educational Psychology, click on PDF Full Text located on the left side of the screen and click on the Search within tab to enter keywords or browse the table of contents by clicking on the Contents tab.

«Contents Search within My Notes
foreign language proficiency
clear results
Keyword Matches (1211 found)
Sort by: Relevancy Chapter / Page


PART II

\section{CHAPTER 2: SEARCHING FOR KNOWN TITLES}

Learning Outcomes

After completing this chapter, you will be able to:

- $\quad$ Search for and find a known title 



\section{2.I Where to Start Searching for Known Titles}

- Watch the introductory video on where to start searching.

A video element has been excluded from this version D1 of the text. You can watch it online here:

https://openeducationalberta.ca/librarylabmanual/?p=131

- Use the Start Your Search box on the main page of the UofA library website to enter book titles or journal titles (ie. words that appear in italics or are underlined in a citation) that you wish to find.

- If you are unsure of how the library catalogue is to be searched, please consult the Search Tips.

- The next chapters will guide you through the process of searching for known titles in the library catalogue. 


\subsection{Searching the Library Catalog for a Known Title}

Your search for a known title will likely start with a reference to a source you wish to find. See the book title below as an example.

Jordan, R., Roberts, J., \& Hume, K. A. (2019). The SAGE Handbook of autism and education. SAGE.

The title of the source can be entered in the UofA Library's Search box, as shown below, or in quotation marks to search for the words together as a phrase, e.g. "SAGE Handbook of autism and education".

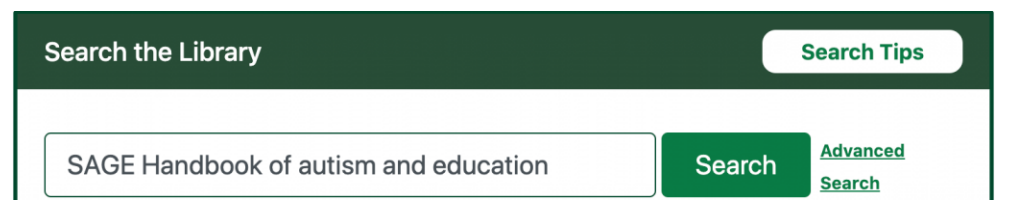

The results presented from the UofA's Search the Library consists of a list of records, ie. descriptions of library titles both in print and electronic formats.

- The book title The SAGE Handbook of autism and education, for example, exists only in electronic format and has one corresponding record. Look through the list of results to find the online title that is available to the University of Alberta. Examine the different parts of a list of records and click on the i symbol to learn about each.

14 | 2.2 Searching the Library Catalog for a Known Title 
An interactive or media element has been excluded

구스 this version of the text. You can view it online

here:

https://openeducationalberta.ca/librarylabmanual/?p=68

- To open the electronic book record, click on the record for the ebook title ${ }^{1}$ in the list of results that is accessible to the University of Alberta as indicated by the wording - Copies owned by: University of Alberta Internet.

See the next chapter for a presentation of library records and how to understand the information they present.

\section{1. https://search.library.ualberta.ca/catalog/8795801}




\subsection{Reading a Catalogue Record}

The library book record for the electronic book The SAGE Handbook of Autism and Education shown below presents useful information for accessing the ebook and its bibliographic information. Subject headings are particularly useful for finding other similar titles. Examine the different parts of a record and click on the $\mathbf{1}$ symbol to learn about each.

\section{An interactive or media element has been excluded

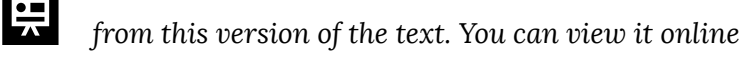

here:

https://openeducationalberta.ca/librarylabmanual/?p=76

The location of the print book Research-Based Practices in Special Education shown below is indicated in the Where is This? box. The information includes the name of the library that holds that book and where it is located on the shelves. This shelving system is organized by call number order. Print library items can be placed on hold and held for a user to pick up by a certain date. Examine the different parts of a record and click on the 1 symbol to learn about each.

An interactive or media element has been excluded from this version of the text. You can view it online 
here:

https://openeducationalberta.ca/librarylabmanual/?p=76

Please see the UofA Library's curbside pickup service information during the Covid-19 library closure. 


\subsection{Book Title Searching Exercise}

Question 1:

An interactive or media element has been excluded 므 from this version of the text. You can view it online here:

https://openeducationalberta.ca/librarylabmanual/?p=146

Question 2:

An interactive or media element has been excluded

믓 from this version of the text. You can view it online here:

https://openeducationalberta.ca/librarylabmanual/?p=146 


\subsection{Finding Journal Articles and Book Chapter Titles}

- The process involved in finding journal article titles is similar to finding book chapters. Both involve searching for the container (ie. journal title or book title) instead of what is contained (ie. the article or the chapter).

- Let's take the following journal article citation example and see how to go about finding access to it.

Wire, V. (2005). Autistic Spectrum Disorders and learning foreign languages. Support for Learning, 20(3), 123-128.

1. Search for the journal title or container of the article in the library catalogue, ie. Support for Learning:

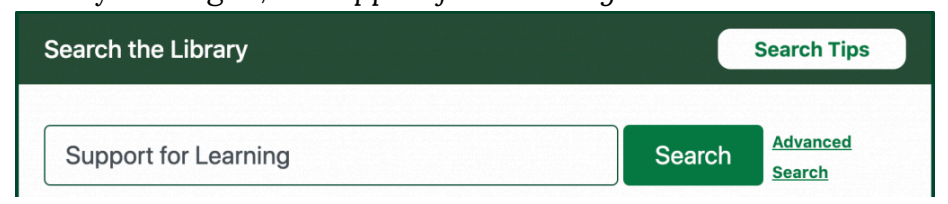

2. Select the journal title, Support for Learning, from the list of results. N.B. The two records with the same title both give access to the online version of the same journal title. Clicking on either will allow you to access the journal. 


\begin{tabular}{|lr|} 
Limit your search \\
\hline Access \\
\hline $\begin{array}{l}\text { At Library } \\
\text { Online }\end{array}$ \\
\hline Institution & 2,436 \\
\hline Library & , \\
\hline Call Number & , \\
\hline Format & , \\
\hline Publication Year & , \\
\hline Author & , \\
\hline Subject & , \\
\hline Language & \\
\hline
\end{tabular}

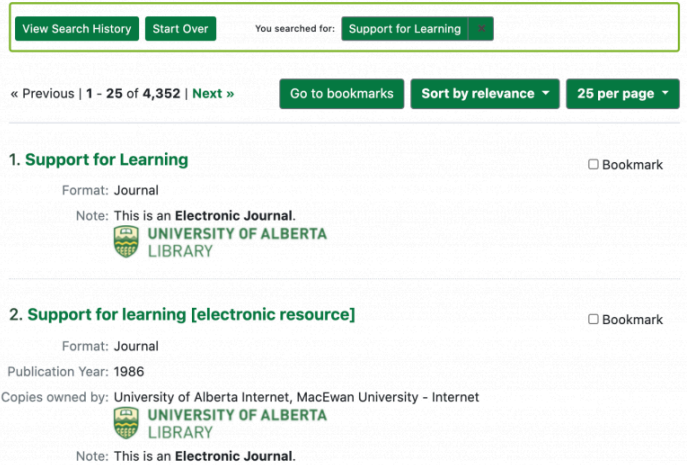

3. Open the journal title record (e.g. the first one in the list above) and select the online journal access appropriate for the year in which the article was published. In the case of the article citation above, 2005 is the year in which the article was published in the journal; therefore, any of the databases listed on the right-hand side in the record shown below would cover articles published in 2005.

\section{Support for Learning}

Full/Alternate Title(s): Support for Learning

Format: Journal

Published: Harlow, Essex

ISSN: 0268-2141

Subjects

- Arts and Humanities

\begin{tabular}{|l|}
\hline Subscriptions \\
\hline $\begin{array}{l}\text { CRKN Wiley Online Library } \\
\text { coverage: Available from } 1997 \text { volume: } 12 \text { issue: } \\
1 .\end{array}$ \\
\hline $\begin{array}{l}\text { EBSCOhost Academic Search Complete } \\
\text { coverage: Available from 1998. Most recent } 1 \\
\text { year(s) not available. }\end{array}$ \\
\hline $\begin{array}{l}\text { Wiley Online Library Education Backfiles } \\
\text { coverage: Available from 1986 volume: } 1 \text { issue: } \\
1 \text { until } 1996 \text { volume: } 11 \text { issue: } 4 .\end{array}$ \\
\hline
\end{tabular}

Conditions of Use

4. Follow the steps in the CRKN Wiley Online Library database image below for locating the full-text of the article. Examine the different steps involved in finding the article full-text, starting with Browse, by clicking on the 1 symbol. 
view it online here:

https://openeducationalberta.ca/librarylabmanual/?p=72 


\subsection{Finding Journal Articles \& Book Chapters Exercise}

The following exercise asks you to locate the full-text of a journal article and a book chapter in a given citation.

Question 1 - Find the full-text of a journal article from the citation below.

Lim, N., O’Reilly, M. F., Sigafoos, J., Ledbetter-Cho, K., \& Lancioni, G. E. (2019). Should Heritage Languages Be Incorporated into Interventions for Bilingual Individuals with Neurodevelopmental Disorders? A Systematic Review. Journal of Autism and Developmental Disorders, 49(3), 887-912.

\footnotetext{
An interactive or media element has been excluded 믓 from this version of the text. You can view it online
} here:

https://openeducationalberta.ca/librarylabmanual/?p=176 
Question 2 - Find the full-text of a book chapter from the citation below.

Green, S. L. \& Edwards, K. M. (2014). Speech and Language Impairments. In A. F. Rotatori, J. P. Bakken, S. Burkhardt, F. E. Obiakor, \& U. Sharma (Eds.), Special Education International Perspectives: Biopsychosocial, Cultural, and Disability Aspects (pp.183-206). Advances in Special Education (Volume 27). Emerald Group Publishing.

An interactive or media element has been excluded from this version of the text. You can view it online here:

https://openeducationalberta.ca/librarylabmanual/?p=176

Please see the next chapter for an alternate way of finding journal and book full-text. 


\subsection{Using the GetIt Citation Linker to Find Source Titles}

Some databases will provide a GetIt Citation Linker Get It @ UAlberta which, when clicked, will provide various full-text access points in a new window. The image below shows where the GetIt linker in the Ebsco database is located (click on the $\mathbf{3}$ symbol for more information).

\section{An interactive or media element has been excluded from this version of the text. You can view it online} here:

https://openeducationalberta.ca/librarylabmanual/?p=74

The full Ebsco record of the journal article shown above and linked here demonstrates that the GetIt linker icon sometimes appears elsewhere in the record (ie. to the left of the bibliographic information).

N.B. not all resources are available in full-text, some may require ordering through interlibrary loans (ILL). 


\section{PART III}

\section{CHAPTER 3: TOPIC SEARCHING}

Learning Outcomes

After completing this chapter, you will be able to:

- $\quad$ Organize a search strategy using concepts and keywords

- Combine concepts and keywords using Boolean logic

- Choose an appropriate database to search

- $\quad$ Search ERIC using an EBSCO platform and PsycInfo using OVID 



\section{I Choosing the Right Tool for the Search Job}

Your research question(s) will determine the kind of search tools you will need to use in order to answer it. The types of sources you wish or need to consult will also help choose the search tool.

Sample Research Question:

What is the foreign language proficiency of elementary-aged children with autism in Alberta schools?

1. If you wish to find an entire book or a video on a topic, e.g. autism, then searching the library catalog's advanced search is a good option.

\section{Advanced Search}

Find items that match all $\sim$ of

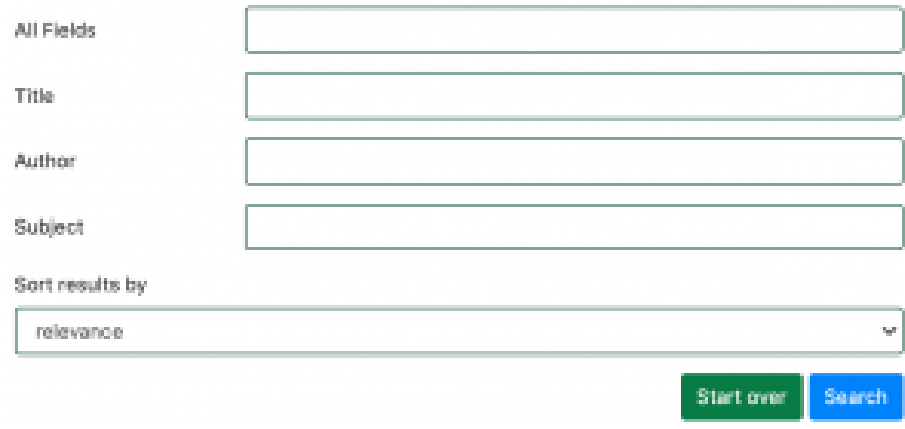

2. If you wish to find journal articles or book chapters, a database is best, e.g. ERIC, listed under Education in its subject guides or the subject area's list of databases. 


\section{Subject Guides}
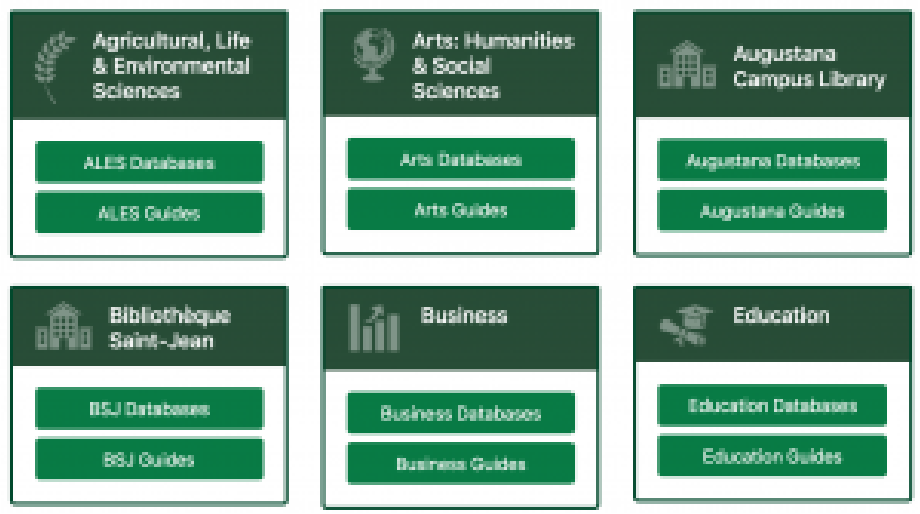

3. The video below will explain where to start searching for information at the University of Alberta Library.

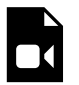

A video element has been excluded from this version of the text. You can watch it online here:

https://openeducationalberta.ca/librarylabmanual/? $p=87$

4. This next video helps understand the various kinds of databases that exist at the University of Alberta Library.

A video element has been excluded from this
version of the text. You can watch it online here:
https://openeducationalberta.ca/librarylabmanual/?p=87

Please see the next chapter to begin determining which concepts you will use to search for information. 


\section{I.I Choosing the Right Tool Exercise}

Use the following research question to answer the two questions below.

\section{What is the foreign language proficiency of} elementary-aged children with autism in Alberta schools?

Question 1: Which of the following subject guides are relevant in answering the research question above? Hint: the information symbol

i beside each answer provides supplementary information on the guides' contents.

An interactive or media element has been excluded from this

믓 version of the text. You can view it online here:

https://openeducationalberta.ca/librarylabmanual/?p=296

Question 2: In the image below, click on the relevant library guides useful to answer the question above.

An interactive or media element has been excluded from this version of the text. You can view it online here: https://openeducationalberta.ca/librarylabmanual/?p=296 


\subsection{Combining Concepts for Topic Searching}

As you try to find information for your assignment, it is likely that you will alternate between known topic or author searching and topic searching.

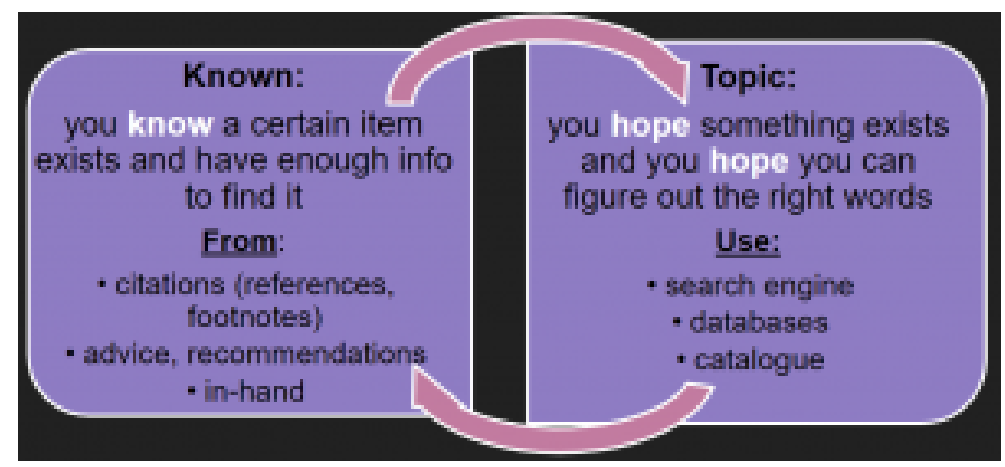

- The video tutorial on how to put a search together within a database will help you understand various strategies for developing a topic search.

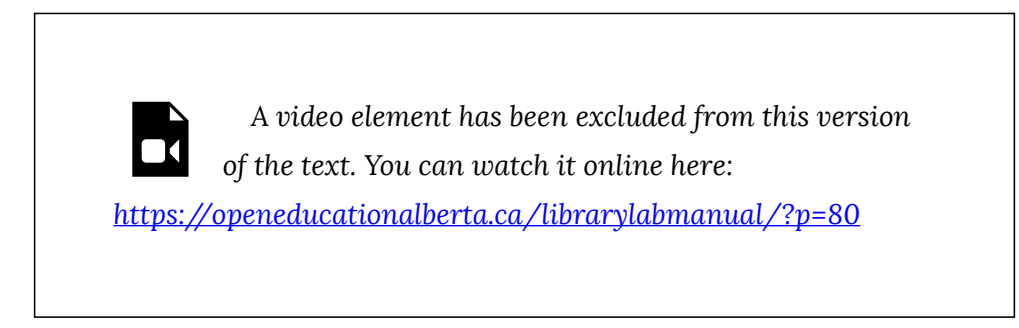

- Divide your research question into at least two concepts.

- For the question What is the foreign language proficiency of elementary-aged children with autism in Alberta schools?

30 | 3.2 Combining Concepts for Topic Searching 
there could be autism as Concept 1 and language learning as Concept 2 and proficiency as Concept 3.

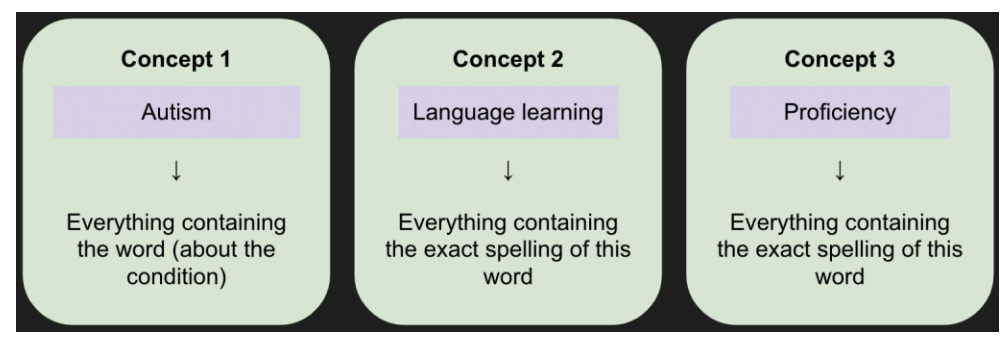

N.B. The more concepts you add to your search the more precise it will be, but the less results you will retrieve. Therefore, if you have more than two concepts and too few results, try changing one or more of the concepts and/or removing a concept to increase the breadth of your search.

Please see the next chapter to begin thinking about the keywords and synonyms that describe each concept. 


\subsection{Using Variant Terms to Describe your Topical Concepts}

Now that you have determined which concepts you will be using to search for information, it is time to begin listing keywords and synonyms that describe each concept. This strategy will help you improve and increase your search results. The video below will give you an overview of this technique.

A video element has been excluded from this version
of the text. You can watch it online here:

https://openeducationalberta.ca/librarylabmanual/?p=82

The three concepts used in the preceding chapter will now serve as an example in identifying their corresponding keywords and synonyms.

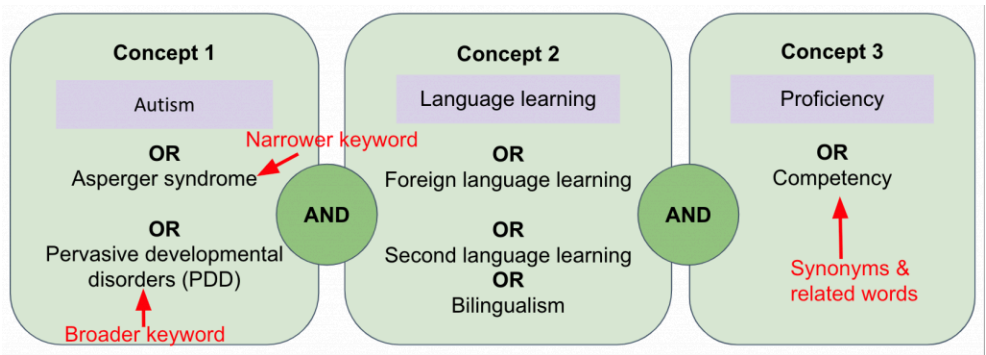

The keywords and subject headings you discover when reading and 
searching for information in the library catalog and other databases will help build the variant terms to describe the concepts. It is important to keep track of them. In chapter 2.3, the image of a catalog record for the The SAGE Handbook of Autism and Education is given and subject headings are highlighted at the bottom of the record. Note the subject heading autistic children, which is relevant to the autism concept and could be added to the concept's list of variant terms.

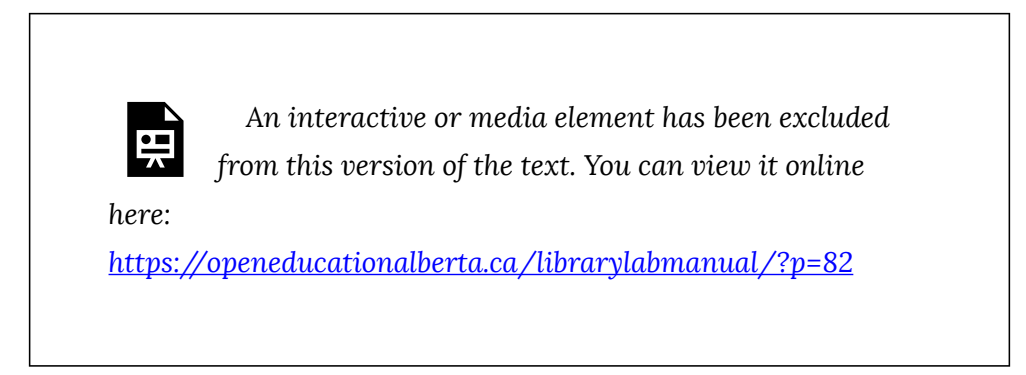

Please see the next chapter for implementing concepts and their variant terms in the context of a database search. 


\subsection{Advanced Searching of the Library Catalog}

Chapter 3.1 recommended searching the library catalog's advanced search, in order to find an entire book or standalone resource on a topic, e.g. autism. The following two images will show how the same search can be constructed in different ways based on the research question concepts and keywords. The $\mathbf{D}$ symbol in the images below will provide information about the search. By clicking on the title Advanced Catalog Search 1 or 2 below, the search will be performed in the library catalog and the list of results will open in a new window.

\section{$\underline{\text { Advanced Catalog Search } 1}$}

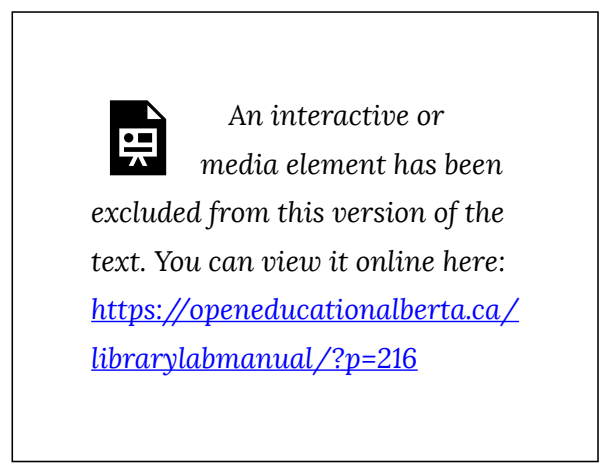

\section{Advanced Catalog Search 2}

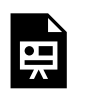

An interactive or media element has been excluded from this version of the text. You can view it online here: https://openeducationalberta.ca/ librarylabmanual $/ ? p=216$

Library Catalog Search Tips:

- Use quotation marks to search as a phrase.

- Use + before a term to make it required. 
- Use - before a word or phrase to exclude.

- Use "OR", "AND", and "NOT" (uppercase, no quotation marks) to create Boolean logic within a field. You can use parentheses in your complex expressions.

- Please watch the following video for information about combining search terms and using Boolean operators in an Ebsco database.

- For more information about using Boolean operators, please watch this other video.

- Word-stemming is done automatically. Truncation and wildcards are not supported (see the next chapter).

The next chapter will present a similar search using the same research question concepts in an article database. 


\subsection{Learning to Search the ERIC (Ebsco) Database}

The ERIC database using the EBSCO platform focuses on a wide range of educational topics and contains references to journal articles, book chapters, reports, and other information source formats. The following examples will be based on the concepts and research question given in chapter 3.3.

\section{What is the foreign language proficiency of elementary-aged children with autism in Alberta schools?}

1. Take each concept and divide them into separate search boxes using OR Boolean operators between each concept keyword (open the search example).

\begin{tabular}{|c|c|c|c|c|}
\hline New Search & Thesauru & \multicolumn{2}{|l|}{ Indexes } & \\
\hline \multirow{4}{*}{ EBSCOhost } & \multicolumn{3}{|c|}{ Searching: ERIC Choose Databases } & \\
\hline & autis & OR pervasive developmental disorder* OR F & Select a Field (optional) - & Search \\
\hline & AND - & foreign language* OR second language ${ }^{*}$ & Select a Field (optional) - & \multirow{2}{*}{$\begin{array}{l}\text { Clear } ? \\
+-\end{array}$} \\
\hline & AND - & proficien* OR competenc* & Select a Field (optional) - & \\
\hline
\end{tabular}

2. First search each concept across all fields using the Select a Field option from the drop-down menu to the right of each concept. 
Note the use of the * truncation symbol at the end of some of the search terms. A truncation symbol accounts for multiple endings of a word and is usually placed at the point where the spelling of the word may change.

3. Examine some of the results to see if your search is providing expected results. The record below shows in bold which search terms appear in the record.

4. An Exploratory Longitudinal Study of Social and Language Outcomes in Children with Autism in Bilingual Home Environments

By: Zhou, Vanessa; Munson, Jeffrey A; Greenson, Jessica. Autism: The International Journal of Research and Practice, v23 n2 p394404 Feb 2019. (EJ1206269)

Subjects: Bilingualism; Early Intervention; Autism; Pervasive Developmental Disorders; Case Studies; Longitudinal Studies; Interpersonal Competence; Correlation; Family Environment; Language Skills; Infants; Toddlers; Nonverbal Communication; Nonverbal Ability; Monolingualism; Comparative Analysis; Social Development; Second Language Learning; Language Acquisition; Language Usage; Adjustment (to Environment); Behavior Rating Scales; Children; Cognitive Ability; Young Children; Motor Development; Measures (Individuals); Family Characteristics; Parent Attitudes; Vineland Adaptive Behavior Scales; Mullen Scales of Early Learning; MacArthur Communicative Development Inventory

GetII Qualberta Plumx Metrics

4. Special attention can be given to the list of subjects. Relevant subjects not in bold can be added to your search to revise and improve it.

Searching: ERIC $\mid$ Choose Databases
\begin{tabular}{|l|l|l|}
\hline autis* OR pervasive developmental disorder* OR F & Select a Field (optional) \\
\hline AND - & bilingual ${ }^{\star}$ OR foreign language ${ }^{*}$ OR second & Select a Field (optional) - \\
\hline AND - & proficien ${ }^{*}$ OR competenc & Select a Field (optional) - \\
\hline
\end{tabular}

Basic Search Advanced Search Search History

5. Note also in the subjects listed in the sample record above that an age concept appears, which can be added to your search as a fourth concept. 
Searching: ERIC Choose Databases

\begin{tabular}{|c|c|c|c|}
\hline \multicolumn{2}{|c|}{ autis* OR pervasive developmental disorder* OR F } & Select a Field (optional) $\mathbf{r}$ & Search \\
\hline AND - & bilingual* OR foreign language* OR second & Select a Field (optional) - & Clear? \\
\hline AND - & proficien* OR competenc* & Select a Field (optional) - & \\
\hline AND - & 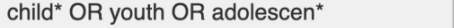 & Select a Field (optional) $\mathbf{v}$ & +- \\
\hline
\end{tabular}

6. To limit your search results it is possible to change which fields are being searched. For example, try limiting one concept at a time to a subject field search. Subjects in ERIC are also called descriptors.

\begin{tabular}{|c|c|c|c|c|}
\hline \multicolumn{3}{|c|}{ autis* OR pervasive developmental disorder* OR PDD } & \multirow{2}{*}{$\begin{array}{l}\text { SU Descriptors } \\
\text { a Field (optional) }\end{array}$} & Search \\
\hline AND - & 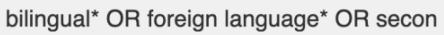 & Selec & & Clear ? \\
\hline AND - & proficien* OR competenc* & Selec & a Field (optional) ${ }^{\top}$ & \\
\hline AND - & child* OR youth OR adolescen* & Selec & a Field (optional) ${ }^{\top}$ & +- \\
\hline
\end{tabular}

7. Use the Thesaurus link at the top of the screen to consult which subjects/descriptors to use in ERIC. For example, the term "foreign language learning" is not a subject/descriptor in ERIC, instead the Thesaurus recommends using "second language learning." Click on the $\mathbf{D}$ symbol in the image below to learn about searching the Thesaurus.

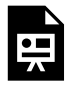

An interactive or media element has been excluded from this version of the text. You can view it online here:

https://openeducationalberta.ca/librarylabmanual/?p=84

8. To further limit your search you can use the Refine Results options located on the left-hand side of the database screen. 
Choose to limit your search by publication dates and source types (e.g. academic journals, books, etc.).

\section{Limit To}

$\square$ Scholarly (Peer Reviewed) Journals

$\square$ IES Funded
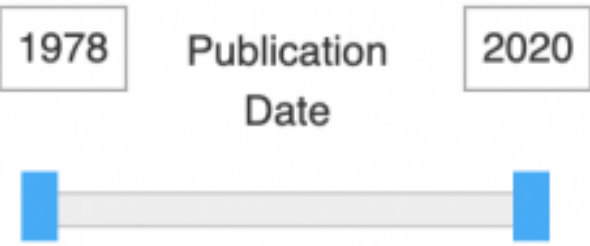

Show More

\section{Source Types}

All Results

$\square$ Reports (22)

$\square$ Academic Journals (19)

$\square$ ERIC Documents (15)

$\square$ Dissertations (6)

\section{$\square$ Books (3)}

9. To expand your search, a few options are available: 
1. remove one or more concepts from your search,

2. add more keywords describing a concept, and/or

3. search keywords within the full-text sources included in ERIC, ie. change the field to TX All text in the drop-down menu next to each search box.

For a general overview of searching ERIC (EBSCO), see the following video.

Please see the next chapter to learn the basics of searching PscyInfo. 


\subsection{Searching PsycInfo (OVID)}

PsycInfo covers international scholarly literature in psychology, including educational psychology. Access the PsycInfo database from the Educational Psychology subject guide or from the list of UofA Education databases. OVID is the vendor platform on which the PsycInfo database is available.

PsycInfo Search Tips

- Advanced Search: Enter each concept and/or keyword one at a time in Advanced Search and select the relevant subject headings listed as a result. Click on the $\mathbf{D}$ symbol in the image below to learn about the various steps involved.

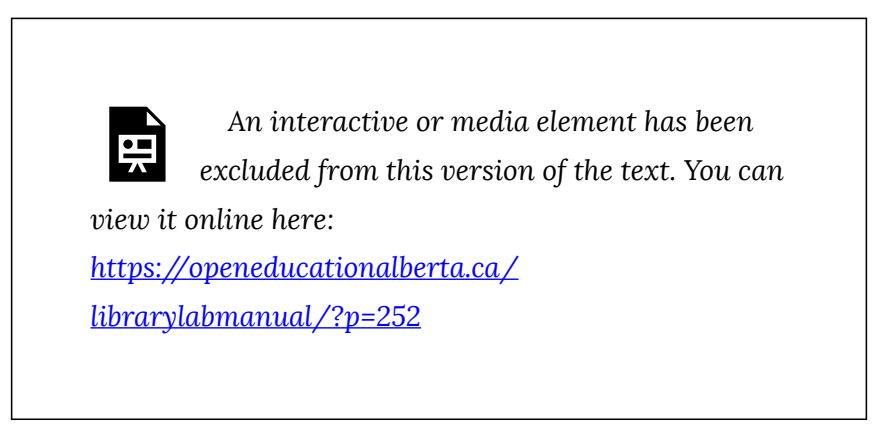

- Subject Heading Mapping: Once you've chosen one or 
more subject headings, choose continue \& repeat the process with your second keyword. Click on the symbol in the image below to learn about the subject mapping feature.

An interactive or media element has been

믓 excluded from this version of the text. You can view it online here:

https://openeducationalberta.ca/

librarylabmanual $/ ? p=252$

Search History: At the top of the screen, look through the list of searches performed. If the first searches are no longer visible, click on the Expand button located to the right of the list.

1. Combine your searches with AND/OR:

1. Combine keywords relating to the same concept with ORs,

2. Repeat for each concept,

3. Combine the concepts with an AND

4. See the video below for a demonstration of the steps above

A video element has been excluded from this version of the text. You can watch it online here:

https://openeducationalberta.ca/librarylabmanual/?p=252

Results are visible below the search box, or click on Display Results in the list of combined searches.

42 | 3.6 Searching PsycInfo (OVID) 
The EdPY subject guide provides more information on searching PsycInfo.

Watch the APA PsycInfo tutorial for more in-depth information on using this database.

Please try the following chapter exercise to practice what you have learned so far. 


\subsection{Database Searching Exercises}

\section{Exercise Research Question:}

How prevalent is secondary traumatic stress among high school teachers in Canada?

Question 1: Which major concepts are present in the research question above?

\footnotetext{
An interactive or media element has been excluded

rom this version of the text. You can view it online
} here:

https://openeducationalberta.ca/librarylabmanual/?p=303

Question 2: Consult PsycInfo to find the subject heading or descriptor used to describe secondary traumatic stress.
읏 An interactive or media element has been excluded from this version of the text. You can view it online here: https://openeducationalberta.ca/librarylabmanual/?p=303

Question 3: In the following exercise, drag and drop in the search boxes the relevant keywords in the order in which they appear as concepts in the research question.

44 3.7 Database Searching Exercises 
An interactive or media element has been excluded from this 믄 version of the text. You can view it online here: https://openeducationalberta.ca/librarylabmanual/?p=303

The next set of chapters focus on evaluating, citing, and managing information. 

PART IV

\section{CHAPTER 4: EVALUATING, \\ CITING, AND MANAGING YOUR SOURCES}

\section{Learning Outcomes}

After completing this chapter, you will be able to:

- Evaluate sources of information for their reliability, authority, and accuracy

- $\quad$ Find resources to help you cite in APA style

- Devise a strategy for managing your sources of information 



\section{I Evaluating Sources}

The following video tutorial on evaluating information will go through the questions to ask to determine the reliability of the sources you find.

A video element has been excluded from this version of the text. You can watch it online here:

https://openeducationalberta.ca/librarylabmanual/?p=89

Determining whether a journal is popular or scholarly is one possibility in limiting your search to more reliable sources. The video on popular and scholarly sources provides a good overview of the characteristics of both types of sources and suggests tools for knowing whether a journal is academic or popular, peer-reviewed/ refereed or not.

\footnotetext{
A video element has been excluded from this version of the text. You can watch it online here:

https://openeducationalberta.ca/librarylabmanual/?p=89
}

Ulrich's database mentioned in the preceding video tutorial has descriptive information about most journal titles and will tell you whether a journal is peer-reviewed/refereed. Ulrich's is accessible by searching the UofA Library's list of databases.

Assessing a source's research methodology is also a good strategy. In the sample PsycInfo record below taken from a peerreviewed journal, one can see that the article is an empirical study 
using quantitative methods in a child population located in Canada. Information about the tests and measures used is also available.

\section{PsycInfo Record Methodology Information}

Ouellette-Kuntz, Helene, Coo, Helen, Lam, Miu, Breitenbach, Marlene M, Hennessey, Paula E, Jackman, Paulette D, et al. (2014). The changing prevalence of autism in three regions of Canada. Journal of Autism and Developmental Disorders, 44, 120-136. https://doi.org/10.1007/s10803-013-1856-1

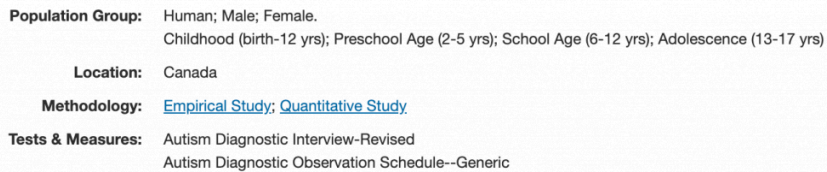

To learn more about research methodologies, please consult the SAGE Research Methods database.

Please see the next chapter to learn about how to cite sources in APA style. 


\subsection{Citing Sources}

- Use the UofA's library citation guide to find resources that will help you cite your sources

- Use the APA QuickGuide linked from the APA citation style page for examples of various sources cited in the APA citation style

- The APA Style Citation Tutorial will help you learn the basics of citing in APA format

- Please note that the "cite tool" available in various databases for producing a citation is not always accurate. It may be a good starting point, but the database's version of the citation needs to be checked for accuracy.

- RefWorks is also a tool you can use to cite your sources and, as explained in the next section, manage them effectively. 


\subsection{Managing Sources}

As you search across databases, it is important to keep track of the search terms you use and where you have searched. Keeping a search diary (e.g. in a Google doc) will help you remember what you have searched where and when. Also remember to note where you have saved the relevant references that have resulted from the searches (e.g. RefWorks).

Saving the complete bibliographical information of the relevant references that result from your searches is crucial to your research. Bibliographical managers, like RefWorks, will help you manage your sources and keep them safe. It is good practice to save your references in multiple locations.

Please try the chapter exercise below to practice what you have learned so far. 


\subsection{Chapter Exercise}

\section{Citation for exercise questions:}

Krop, J. (2013). Caring without tiring: Dealing with compassion fatigue burnout in teaching. Education Canada, 53(2), 42.

Question 1: Use the Ulrich's database to determine what type of journal published the article described above.

An interactive or media element has been excluded from this

믄 version of the text. You can view it online here: https://openeducationalberta.ca/librarylabmanual/?p=310

Questions 2: To properly cite this article, you will need to know whether it is available electronically or in print. Please search the library catalogue for the journal title and determine whether the article is available online or in print.

An interactive or media element has been excluded from this

믄 version of the text. You can view it online here: https://openeducationalberta.ca/librarylabmanual/?p=310

Question 3: In the reference above, which APA elements, if any, are missing?

An interactive or media element has been excluded from this version of the text. You can view it online here: https://openeducationalberta.ca/librarylabmanual/?p=310 



\section{AskUs}

\begin{tabular}{llllll}
\hline UNIVERSITY OF ALBERTA & $\begin{array}{l}\text { Library } \\
\text { Services }\end{array}$ & $\begin{array}{l}\text { Subject } \\
\text { Guides } \\
\text { LIBRARY }\end{array}$ & $\begin{array}{l}\text { Hours \& } \\
\text { Locations }\end{array}$ & $\begin{array}{l}\text { About the } \\
\text { Library }\end{array}$ & $\begin{array}{l}\text { My } \\
\text { Account }\end{array}$
\end{tabular}

If you have any questions about finding, evaluating, and citing information, please talk to staff by chat or email using the UofA Library's AskUs service, linked on the right-hand side of the banner as shown above.

If you would like to contact subject librarians, please find them listed by subject area. 


\section{Glossary}

\section{Citation}

A cited passage or quotation.

\section{Concept}

A major topic included in a research question.

\section{Database}

A collection of data (e.g. article or book titles, full-text) searchable and available electronically

\section{Ebook}

Electronic book

\section{Ebsco}

EBSCO is a provider of research databases, e-journals, magazine subscriptions, e-books and discovery service to libraries of all kinds.

\section{ERIC}

ERIC contains records and links to hundreds of thousands of full-text documents. It includes records for a variety of source types, including journal articles, books, conference papers, curriculum guides, dissertations and policy papers. Further, researchers can limit search results by education level such as Early Childhood Education as well as on the intended audience such as Counselors or Teachers. 


\section{Full-text}

The complete text of a book or article

\section{Hold}

A term used to describe the process of requesting that a library item be sent or returned to a library branch and held for a specific person for a short period of time.

\section{Journal}

A periodically published set of articles that may take the form of an academic periodical, magazine, or newspaper.

\section{Keyword}

A term used to describe a source of information, e.g. words in a title, names of authors, subject headings, place of publication, etc.

\section{Ovid}

A Wolters Kluwer provider of research databases focusing on areas like health, behavioural sciences, etc.

\section{Primary Source}

Information that is a result of first-hand experience or original research.

\section{PsycInfo}

Also known as APA PsycInfo. It covers the international literature in psychology. Topics include: applied psychology, communication systems, developmental psychology, education psychology, experimental psychology, personality, physical and psychological disorders, physiological psychology, psychometrics, social psychology and sports psychology. 
Formats covered by this database are: journal articles, book chapters, dissertations and technical reports.

\section{Record}

A bibliographical description of a published work in a library catalogue or database.

\section{Reference or Cited reference}

A cited work listed and systematically described in a list of references.

\section{Reference Title}

A publication that can be considered a tertiary source, e.g. dictionaries, handbooks, encyclopedias

\section{Secondary Source}

Information that is derived from primary sources or original research, e.g. second hand information.

\section{Subject guide}

An online library help manual

\section{Tertiary Source}

Information that derives from primary and secondary sources, like dictionaries, encyclopedias, etc. 